\title{
Mycotic Aneurysm Treated with Aneurysm Trapping. Case Report
}

\author{
Sérgio Neto ${ }^{1}$ Juan Castro Flores ${ }^{1}$ Eberval Gadelha Figueiredo ${ }^{1}$ José Guilherme Pereira Caldas ${ }^{2}$ \\ Manoel Jacobsen Teixeira ${ }^{1}$ \\ ${ }^{1}$ Division of Neurosurgery, University of Sao Paulo Medical School, Sao \\ Paulo, Sao Paulo, Brazil \\ 2 Division of Interventional Radiology, Hospital das Clinicas, University \\ of São Paulo Medical School, Sao Paulo, Sao Paulo, Brazil \\ Address for correspondence Dr. Sérgio Neto, MD, Division of \\ Neurosurgery, University of Sao Paulo Medical School, Rua Eneas de \\ Carvalho Aguiar 255, Sao Paulo 05403-000, SP, Brazil \\ (e-mail: sgsnnc@gmail.com).
}

J Neurol Surg Rep 2016;77:e13-e16.
Abstract
Keywords
- mycotic aneurysm
- subarachnoid hemorrhage
- endocarditis

The authors describe a rare case of mycotic aneurysm (MA) associated with subarachnoid hemorrhage treated with aneurysm trapping. The literature on management and the surgical techniques are controversial due to lack of randomize trials.

\section{Introduction}

Mycotic cerebral aneurysm is one of many lesions due to infective endocarditis (IE) but still rare and potentially fatal complication. Medical treatment is based on antibiotics and in specific cases surgical treatment is required (craniotomy or endovascular). The absence of randomized trials generates a lack of consensus regarding the management of unruptured aneurysms. We present a case report of a patient diagnosed and treated surgically with improvement on follow-up with the trapping technique of the aneurysm.

\section{Case Report}

A 32-year-old man presented with sudden headache, highgrade fever with chills, and right hemiparesis. Sought medical attention and on the examination of admission, he was febrile $\left(38^{\circ} \mathrm{C}\right)$. The pulse rate was regular $(76$ beats $/ \mathrm{min})$ and blood pressure was 130/70 mm Hg. Cardiac auscultation revealed soft first heart sound, normal aortic component, and a grade 3/6 mitral murmur. On neurologic examination he presented alert and conscious, with a right paretic gait and muscular strength grade I right-sided hemiparesis. After the new diagnosis of a febrile syndrome plus pyramidal syndrome the initial investigation was performed.

received

July 17, 2015

accepted

September 26, 2015

published online

November 16, 2015

\section{Investigations}

Hemogram revealed leucocytosis $\left(11,000 / \mathrm{mm}^{3}\right)$ with predominant neutrophilia (70\%) and normal platelet count $(190,000)$. Urine examination, renal function test, and liver function test were normal. Transthoracic echocardiogram revealed a mitral thickening with perforation leading to severe mitral regurgitation with two jets.

Blood cultures (four samples) were positive after for Abiotrophia defectiva after 96 hour by the matrix-assisted laser desorption/ionization (MALDI TOF) MS method.

Computed tomographic (CT) angiogram and angiography revealed an M2 aneurysm with subarachnoid hemorrhage (SAH) (-Figs. 1 and $\mathbf{2}$ ).

\section{Treatment}

The patient was treated with antifailure medications along with injectable antibiotics for IE for 8 weeks.

The patient was submitted to surgery (pterional craniotomy) with trapping of the aneurysm with success.

\section{Outcome and Follow-up}

The patient was treated with antibiotics and close monitoring for eventual neurologic symptoms worsening. The patient became afebrile and the symptoms leading to heart failure improved with the medical therapy after 10 days. After
License terms

Stuttgart · New York

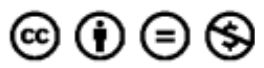




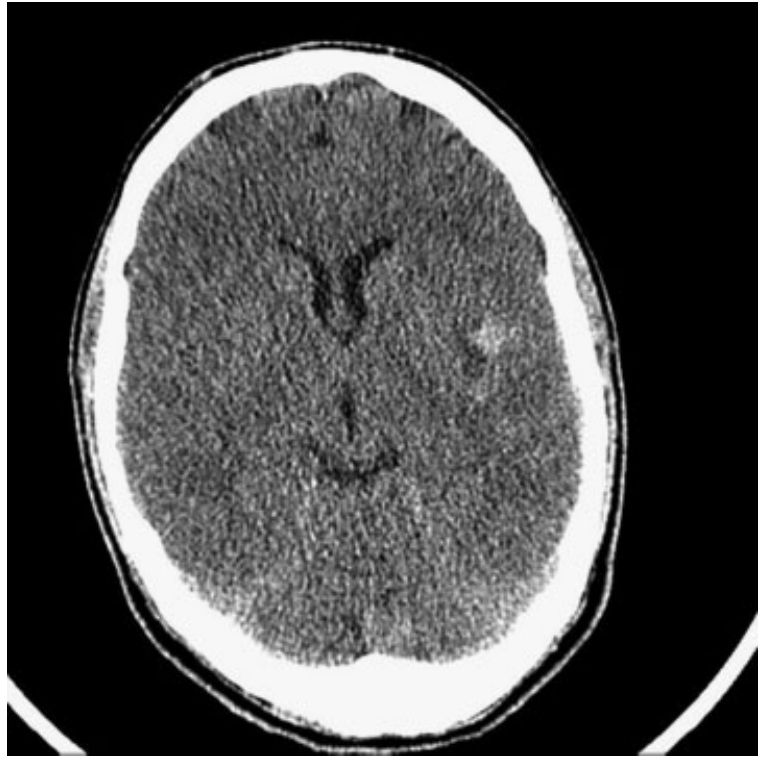

Fig. $1 \mathrm{CT}$ of the head with Fisher IV subarachnoid hemorrhage (SAH).

8 weeks we performed a control magnetic resonance imaging (MRI) angiogram who revealed that the previous lesion increased (-Fig. 3). After surgery the patient improved the previous deficit on 3 months follow-up (from grade I-IV hemiparesis) (-Fig. 4).

\section{Discussion}

The epidemiologic profile of IE has changed substantially over the last few years, especially in industrialized nations. Newer predisposing factors have emerged-valve prostheses, degenerative valve sclerosis, intravenous drug abuse-associated with increased use of invasive procedures at risk for bacteremia, resulting in health care-associated IE. ${ }^{1}$

In developed countries, the incidence of IE ranges from 3 to 9 cases per 100,000 per year, and it is twice as common in men. ${ }^{1}$

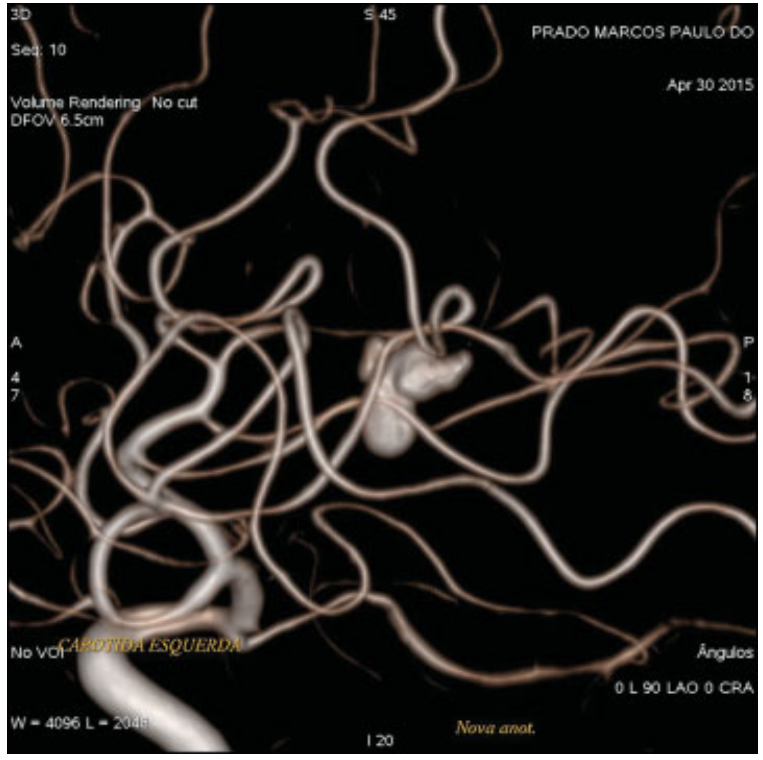

Fig. 3 Angiogram revealing increase of the lesion.

Staphylococcus aureus is the most common organism. Up to $30 \%$ of those having bacteremia with Staphylococcus will develop endocarditis and $75 \%$ of patients with IE have structural abnormalities on their hearts., ${ }^{1,2}$

A. defectiva, a nutritionally variant Streptococcus (NVS), represents a rare but clinically important cause of IE initially described by Frenkel and Hirsch in $1961^{3}$ as fastidious grampositive bacterium and modified by Bouvet et al in $1989^{4}$ who proposed the names Streptococcus defectivus and Streptococcus adjacens, following the use of DNA-DNA hybridization studies. ${ }^{1,5,6}$

A. defectiva endocarditis is a rare cause of endocarditis with rates around $5 \%$ of all cases of streptococcal endocarditis. There are around 100 cases of $A$. defectiva endocarditis in the literature. It predominantly occurs in the setting of preexisting heart disease (90\%); prosthetic heart valves are involved in $10 \%$ of patients. There are no published cases on adults
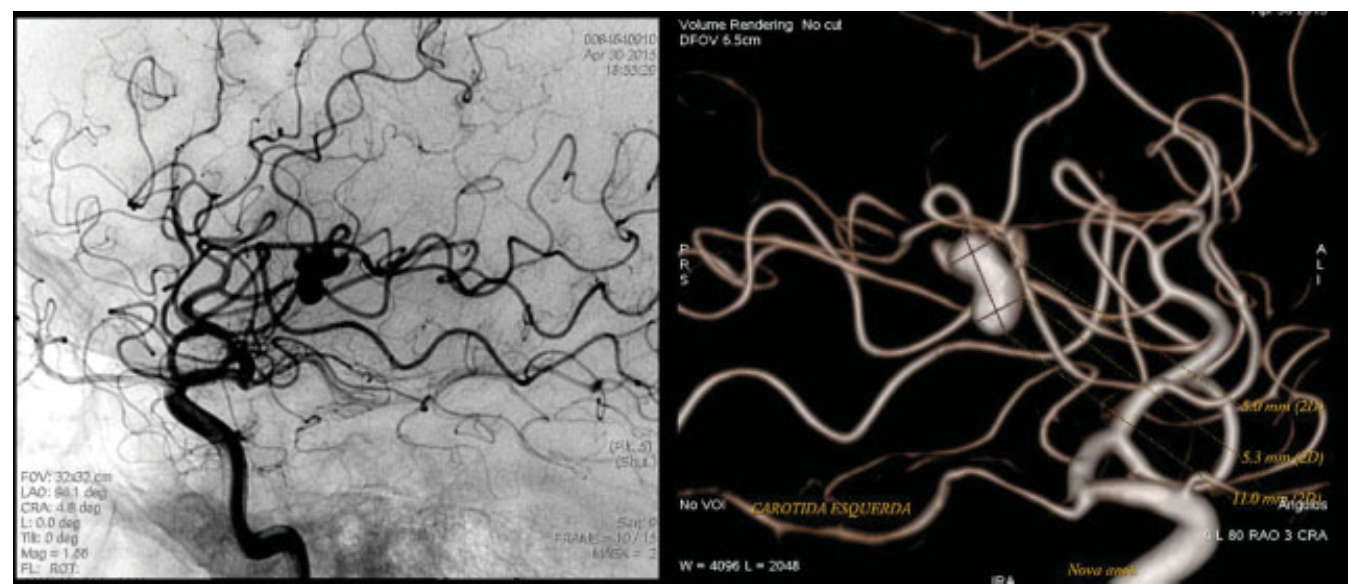

Fig. 2 MCA M2 segment aneurysm. 


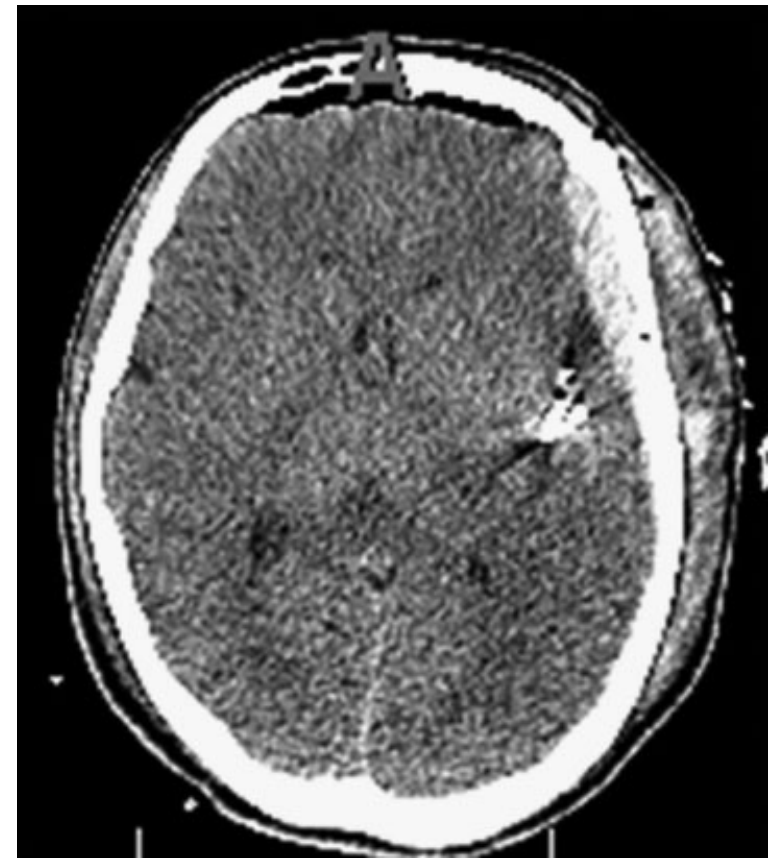

Fig. 4 Post-op CT.

without previously documented valvular heart disease developing. ${ }^{5,6}$

The 1-year rate of IE mortality is around 30\%. Neurologic complications, most commonly cerebral embolism, are seen in 20 to $40 \%$ of the patients and are associated with high morbidity and mortality. The reported incidence of mycotic cerebral aneurysms is 2 to $3 \%$ of all the patients with IE. This is possibly underestimated, because most patients remain asymptomatic and the aneurysm may resolve after antibiotic therapy. ${ }^{2,7}$

The symptoms usually include headache (83\%), fever (67\%), vomiting (50\%), ocular palsy $(25 \%)$, seizures $(21 \%)$, behavioral changes (21\%), hemiparesis $(21 \%)$, drowsiness (17\%), and loss of consciousness $(17 \%)^{1,7}$
The clinical diagnosis of IE is usually made based on modified Duke criteria and the neurologic complications with CT and magnetic resonance angiography. ${ }^{1,7}$

Authors such as Thuny et $\mathrm{al}^{8}$ reported that cerebral and thoracoabdominal CT revealed silent emboli in only $8 \%$ of patients. Cooper et $\mathrm{al}^{9}$ performed MRI of the brain in 40 patients with IE and found acute brain embolization in $80 \%$ of patients. $^{10}$

Several authors have recommended the antimicrobial therapy tailored by culture for 6 to 8 weeks along with close follow-up as the first line of treatment for unruptured intracranial aneurysms and serial imaging. Invasive procedures (microsurgery/endovascular) are indicated for very large, enlarging, or ruptured aneurysm., 10

Surgical management of mycotic aneurysm (MA) depends on several factors, including size, location, expertise of the surgeon (on microsurgery or endovascular) (-Table $\mathbf{1}$ ), and if the aneurysm has ruptured. There are no data comparing microsurgery versus endovascular. ${ }^{11,12}$ Ruptured MAs are managed by either open or endovascular means, following which a 2- to 3-week delay is recommended prior to cardiac valve replacement. Microsurgery in this case is technically difficult, as MAs tend to be fusiform with poorly defined necks and friable walls. Proximal ligation is therefore often necessary. Anastomotic procedures that can spare distal vessels in eloquent areas are sometimes possible. Endovascular therapies are less invasive alternatives that may be more appropriate in patients who are unfit for surgery due to cardiac disease. Detachable coils are preferred for proximal aneurysms, whereas distal aneurysms that are not accessible to microcatheters can be managed with acrylic glue or autologous clot injections. ${ }^{2,11,12}$

\section{Conclusion}

IE is a serious disorder very often in developing countries that is frequently complicated when associated with neurologic disease including ischemic and hemorrhagic stroke. The surgical management of the underlying disease still lacks of randomized trials and sets a new opportunity for new studies

Table 1 Presentation of reported patients treated with endovascular versus current patient (microsurgery)

\begin{tabular}{|c|c|c|c|c|c|c|}
\hline Reference (year) & Age (y) & Clinical presentation & Etiology & Pathogen & $\begin{array}{l}\text { Follow-up } \\
\text { (mo) }\end{array}$ & $\begin{array}{l}\text { Modified } \\
\text { Rankin } \\
\text { Scale score }\end{array}$ \\
\hline Current patient, 2015 & 32 & $\begin{array}{l}\text { Fever, headache, } \\
\text { and hemiplegia }\end{array}$ & Bacterial & Abiotrophia defectiva & 3 & 0 \\
\hline Ding et al, $2014^{13}$ & 35 & Diplopia & $\begin{array}{l}\text { Bacterial } \\
\text { endocarditis }\end{array}$ & Streptococcus mitis & 3 & 0 \\
\hline Sugg et al, $2006^{14}$ & 47 & $\begin{array}{l}\text { Hemiplegia, } \\
\text { headache }\end{array}$ & $\begin{array}{l}\text { Bacterial } \\
\text { endocarditis }\end{array}$ & Unknown & None & 3 \\
\hline Yen et al, $2007^{15}$ & 46 & Ophthalmoplegia & Meningitis & $\begin{array}{l}\text { Streptococcus } \\
\text { constellatus }\end{array}$ & 6 & 1 \\
\hline Appelboom et al, $2007^{16}$ & 10 & Ophthalmoplegia & Meningitis & $\begin{array}{l}\text { Streptococcus } \\
\text { pneumoniae }\end{array}$ & 3 & 0 \\
\hline
\end{tabular}


regarding the matter. A multidisciplinary collaborative approach is critical to optimizing outcomes.

\section{Disclosures}

The authors declared no potential conflicts of interest.

\section{References}

1 Habib G, Hoen B, Tornos P, et al; ESC Committee for Practice Guidelines; Endorsed by the European Society of Clinical Microbiology and Infectious Diseases (ESCMID) and the International Society of Chemotherapy (ISC) for Infection and Cancer. Guidelines on the prevention, diagnosis, and treatment of infective endocarditis (new version 2009): the Task Force on the Prevention, Diagnosis, and Treatment of Infective Endocarditis of the European Society of Cardiology (ESC). Eur Heart J 2009;30(19): 2369-2413

2 Morris NA, Matiello M, Lyons JL, Samuels MA. Neurologic complications in infective endocarditis: identification, management, and impact on cardiac surgery. Neurohospitalist 2014;4(4):213-222

3 Frenkel A, Hirsch W. Spontaneous development of L forms of streptococci requiring secretions of other bacteria or sulphydryl compounds for normal growth. Nature 1961;191:728-730

4 Bouvet A, Grimont F, Grimont P. Streptococcus defectivus sp. nov. and Streptococcus adjacens sp. nov., nutritionally variant streptococci from human clinical specimens. Int J Syst Bacteriol 1989;39:290-294

5 Kiernan TJ, O'Flaherty N, Gilmore R, et al. Abiotrophia defectiva endocarditis and associated hemophagocytic syndrome-a first case report and review of the literature. Int J Infect Dis 2008;12(5): 478-482

6 Baddour LM, Wilson WR, Bayer AS, et al; Committee on Rheumatic Fever, Endocarditis, and Kawasaki Disease; Council on Cardiovascular Disease in the Young; Councils on Clinical Cardiology, Stroke, and Cardiovascular Surgery and Anesthesia; American Heart Association; Infectious Diseases Society of America. Infective endocarditis: diagnosis, antimicrobial therapy, and management of complications: a statement for healthcare professionals from the Committee on Rheumatic Fever, Endocarditis, and Kawasaki Disease, Council on Cardiovascular Disease in the Young, and the Councils on Clinical Cardiology, Stroke, and Cardiovascular Surgery and Anesthesia, American Heart Association: endorsed by the Infectious Diseases Society of America. Circulation 2005;111(23): e394-e434

7 Singla V, Sharma R, Nagamani AC, Manjunath CN. Mycotic aneurysm: a rare and dreaded complication of infective endocarditis. BMJ Case Rep 2013;2013;

8 Thuny F, Disalvo G, Belliard O, et al. Risk of embolism and death in infective endocarditis: prognostic value of echocardiography-a prospective multicenter study. Circulation 2005; 112:69-75

9 Cooper HA, Thompson EC, Laureno R, et al. Subclinical brain embolization in left-sided infective endocarditis: results from the evaluation by MRI of the brains of patients with leftsided intracardiac solid masses (EMBOLISM) pilot study. Circulation 2009;120(7):585-591

10 Meshaal MS, Kassem HH, Samir A, Zakaria A, Baghdady Y, Rizk HH. Impact of routine cerebral $C T$ angiography on treatment decisions in infective endocarditis. PLoS ONE 2015;10(3):e0118616

11 Bohmfalk GL, Story JL, Wissinger JP, Brown WE Jr. Bacterial intracranial aneurysm. J Neurosurg 1978;48(3):369-382

12 Gillinov AM, Shah RV, Curtis WE, et al. Valve replacement in patients with endocarditis and acute neurologic deficit. Ann Thorac Surg 1996;61(4):1125-1129, discussion 1130

13 Ding D et al. Endovascular stenting for treatment of mycotic intracranial aneurysms. J Clin Neurosci 2014;21:1163-1168

14 Sugg RM, Weir R, Vollmer DG, et al. Cerebral mycotic aneurysms treated with a neuroform stent: technical case report. Neurosurgery 2006;58:E381 [discussion E]

15 Yen PS, Teo BT, Chen SC, et al. Endovascular treatment for bilateral mycotic intracavernous carotid aneurysms. Case report and review of the literature. J Neurosurg 2007;107:868-872

16 Appelboom G, Kadri K, Hassan F, et al. Infectious aneurysm of the cavernous carotid artery in a child treated with a new-generation of flow-diverting stent graft: case report. Neurosurgery 2010;66: E623-E624 [discussion E4] 